\title{
Application of MCDM based hybrid optimization tool during turning of ASTM A588
}

\author{
Himadri Majumder ${ }^{\mathrm{a}}$ and Abhijit Saha ${ }^{\mathrm{b}^{*}}$
}

${ }^{a}$ Department of Mechanical Engineering, National Institute of Technology, Rourkela - 769008, India ${ }^{b}$ Department of Production Engineering, Haldia Institute of Technology - 721657, India

\section{H R O N I C L E}

Article history:

Received January 16, 2017

Received in revised format: May 22, 2017

Accepted June 6, 2017

Available online

June 6, 2017

Keywords:

ASTM A588 steel

Multi criteria

MOORA

PCA

Turning

TOPSIS

\section{A B S T R A C T}

Multi-criteria decision making approach is one of the most troublesome tools for solving the tangled optimization problems in the machining area due to its capability of solving the complex optimization problems in the production process. Turning is widely used in the manufacturing processes as it offers enormous advantages like good quality product, customer satisfaction, economical and relatively easy to apply. A contemporary approach, MOORA coupled with PCA, was used to ascertain an optimal combination of input parameters (spindle speed, depth of cut and feed rate) for the given output parameters (power consumption, average surface roughness and frequency of tool vibration) using $L_{27}$ orthogonal array for turning on ASTM A588 mild steel. Comparison between MOORA-PCA and TOPSIS-PCA shows the effectiveness of MOORA over TOPSIS method. The optimum parameter combination for multi-performance characteristics has been established for ASTM A588 mild steel are spindle speed $160 \mathrm{rpm}$, depth of cut $0.1 \mathrm{~mm}$ and feed rate $0.08 \mathrm{~mm} / \mathrm{rev}$. Therefore, this study focuses on the application of the hybrid MCDM approach as a vital selection making tool to deal with multi objective optimization problems.

(C) 2018 Growing Science Ltd. All rights reserved.

\section{Nomenclature}

MOORA

MCDM

PCA

TOPSIS

ANOVA

ANN

GRA

MMAW

$L_{27}$

MRR

* Corresponding author.

E-mail address: alfa.nita2010@gmail.com (A. Saha)

(C) 2018 Growing Science Ltd. All rights reserved. doi: $10.5267 /$ j.ds1.2017.6.003
Multi-objective Optimization on the Basis of Ratio Analysis.

Multi Criterion Decision-Making.

Principal Component Analysis.

Technique for Order of Preference by Similarity to Ideal Solution.

Analysis of Variance.

Artificial Neural Network.

Grey Relational Analysis

Manual metal arc welding

Orthogonal array of 27 runs.

Material Removal Rate 


\section{Introduction}

One of the most basic metal cutting operations, turning constitutes the majority of lathe work. In turning cutting tool, single point, rotates parallel to the axis of rotation to expel unwanted material from the rotating surface of a conical work piece or cylindrical. Turning, oldest machine tools, typically carried out on a lathe can be of various natures like straight or taper turning, external grooving, profiling, etc. It can be done on external as well as internal surface of the work-piece. By using different attachments in lathe flat as well as curved surfaces, conical or grooved work-piece can be produced by turning. Therefore, it is very much essential to hike tool life, improve surface structure and accuracy, and reduce power consumption, frequency of tool vibration and cutting force through optimization study. Among these different responses, power consumption, frequency of tool vibration and average surface roughness play important roles in the performance of machined surface. It observed in the literature that among the different turning parameters, spindle speed, depth of cut and feed rate immensely influence the performance measures. To build up the aspect of machined parts within reduced machining cost having consideration for the improvement of machine efficiency, it is necessary that we should select the most appropriate and optimal machining parameters.

To face the difficulties of worldwide competitiveness, manufacturing associations are confronting the concern of choosing most preferred procedures, design of product, machine, equipment and process. It turns out to be more mind startle as they're heaps of preferences in the perspective of contrary criteria. To offer these determination some assistance with processing, many Multi Criterion Decision-Making (MCDM) techniques are presently available. MCDM specifies making decisions on the existence of contrary multiple criteria. It is used as potential tools for analyzing complicated real problems for possible selection of the suitable or best alternatives due to cost effectiveness for all machining processes. Depending on the nature of the solutions different names are given to different MCDM problems because it may not have a unique or conclusive solution.

By using Taguchi method with GRA, Lin (2004) optimized different input criterion like feed rate, cutting depth and cutting speed in turning operations. Influential attribute like cutting force, tool life and surface roughness were taken as performance characteristics in that research. Wang and Lan (2008) examined MRR, ratio of tool wear and surface roughness, to optimize, using grey relational grade, input variables like speed, tool nose run off, cutting depth, feed rate etc. on ECOCA-3807 CNC Lathe for precision turning. Muthukrishnan and Davim (2009) forecast the surface roughness using ANOVA and ANN for different feed rate, cutting speed and depth of cut for Al-SiC (20\%) composite bars using the PCD insert in turning operation. Davim et al. (2008) predict surface roughness model for $R_{a}$ and $R_{t}$ using ANN for free machining steel turning using $\mathrm{L}_{27}$ orthogonal array for cemented carbide as inserts. They showed that cutting speed and feed rate having a significant effect to reduce surface roughness, whereas depth of cut was least effective. Multiple neural network and linear regression models were developed by Ozel et al. (1997) for forecasting surface roughness in AISI D2 steels finish turning adopting ceramic wiper as inserts. Cutting time, feed rate and cutting speed were treated as input variables for experiment and compared with experimental data. Khan and Maity (2016b) applied MCDM approach Vikor Analysis combined with ANOVA for simultaneous optimization of pure titanium grade 2 in turning. They took depth of cut, cutting speed and feed rate to optimize surface quality, cutting force and MRR. Dey and Chakraborty (2016) studied machinability characteristics of aluminum, steel and copper alloys using grey TOPSIS method and proposed TOPSIS as a suitable method for decision-making problems. Researchers (Khan \& Maity, 2016a) proposed MCDM-based TOPSIS method to optimize different modern manufacturing processes by taking previous researcher work.

Despite the fact that, in modern era, considerable multi criterion decision making technique is accessible for differing assessment and selection problems, MOORA is observed to be computationally easy and simple. 
Gadakh et al. (2013) observed that compare to other MCDM processes MOORA is simple and ease to implement as it associate with less mathematical calculations. They successfully implemented MOORA method for different MCDM problem for various welding processes. Gadakh (2010) carry out MOORA for milling. Khan and Maity (2016c) exhibit MOORA method for different nonconventional processes and shows that it is a robust, easily operational, time saving and simple calculative MCDM technique. For various material selection problems Karande and Chakraborty (2012) used MCDM approach MOORA.

In order to optimize the multiple performance characteristics, MOORA approach was not practiced directly in the current study. Since the contribution of each performance characteristic may not have the same influence in the real life solution. With a specific end goal to find the relative impact of every performance criterion a statistical procedure called principal component analysis (PCA) has been employed to determine the weighting percentage of every performance parameter.

PCA was proposed and defined by Pearson (1901). Antony (2000) practiced PCA approach for multi criteria optimization of submerged arc welding process. Jean and Wang (2006) have reported that to develop a robust, immense effective, high quality EBM process the use of the Taguchi based experiments coupled with PCA is an uncomplicated, adequate and efficient way. Saha and Mondal (2016b) proposed PCA in combination with GRA for simultaneous optimization of WEDM process parameters for nanostructured hard facing material. Yih-Fong and Fu-Chen (2006) integrates PCA with Taguchi method for multi-objective process optimization in $\mathrm{CNC}$ turning of tool steels. Following $\mathrm{L}_{18}$ orthogonal array they investigate eight variables which comprise cutting speed, shape of insert, feed and chip breaker geometry, depth of cut, coating type, coolant, and nose radius. Their main aim was to minimize dimensional precision and surface roughness and also maximizes the accuracy. Ray (2016) proposed GRA with PCA to solve MCDM problem in green electrical discharge machining by developing an analytical structure. They used PCA to find out the weightage of every response which influence the gray relational grades. Saha and Mondal (2016c) practiced PCA coupled with GRA to optimize welding Parameters in MMAW for hard facing material. Majumder et al. (2017) showed hybrid GRA-PCA gives less percentage error compare to traditional GRA, which explains effectiveness of PCA.

Although different optimization and modeling approach has been used for the analysis of the performance characteristics of turning operation, but very few work has been done using hybrid MOORA-PCA. Current learning demonstrates MOORA coupled with PCA for turning to find out a preferable machining parameter combination for ASTM A588. Moreover hybrid MCDM approach namely TOPSIS-PCA was also used to compare the results with the MOORA-PCA.

\section{Experimental Procedure and Test Results}

\subsection{Materials Used}

ASTM A588 is a low-alloy and high strength steel, exhibits high strength and strength-to-weight properties having high atmospheric corrosion resistance. This alloy widely used in bridges, construction equipment, heat exchangers, smoke stack liners, transmission towers, etc. mainly in exterior applications where it can develop corrosion resistant orange-brown surface. ASTM A588 mild steel was taken as work-piece material having a diameter of $25 \mathrm{~mm}$. The Chemical composition of ASTM A588 mild steel is shown in Table 1.

Table 1

Chemical composition of ASTM A588

\begin{tabular}{ccccccccccc}
\hline Material & $\mathrm{C}$ & $\mathrm{Mn}$ & $\mathrm{Si}$ & $\mathrm{Ni}$ & $\mathrm{S}$ & $\mathrm{Cu}$ & $\mathrm{Cr}$ & $\mathrm{P}$ & $\mathrm{N}$ & $\mathrm{V}$ \\
\hline Weight Percentage (\%) & 0.19 & $0.80-1.25$ & $0.30-0.65$ & 0.40 & 0.05 & $0.25-0.40$ & $0.40-0.65$ & 0.04 & 0.01 & $0.02-0.10$ \\
\hline
\end{tabular}




\subsection{Experimental details}

Experimental lathe setup was used for the experiments (shown in Fig.1). In our experiment for turning operation, we used square shaped cemented carbide cutting tool insert. Taguchi's $L_{27}$ orthogonal array used to design our experiment with three factors having three different levels. Taguchi method, a robust design method, reduces the sum of experiment, required to find response activity, exceptionally compared to other conventional approaches (Palanikumar, 2006).Cutting forces measured using Lathe tool dynamometer (shown in Fig.2) and cutting tool vibration measured using PicoScope 2202 (shown in Fig. 3).Average surface roughness $\left(R_{a}\right)$ of the each machined samples found out using Mar Surf PS1 surface roughness tester. The power to perform machining can be computed from:

$$
P_{c}=F \times V
$$

where, $P_{c}=$ Cutting power; $F=$ Main cutting force; and $V=$ Cutting speed.

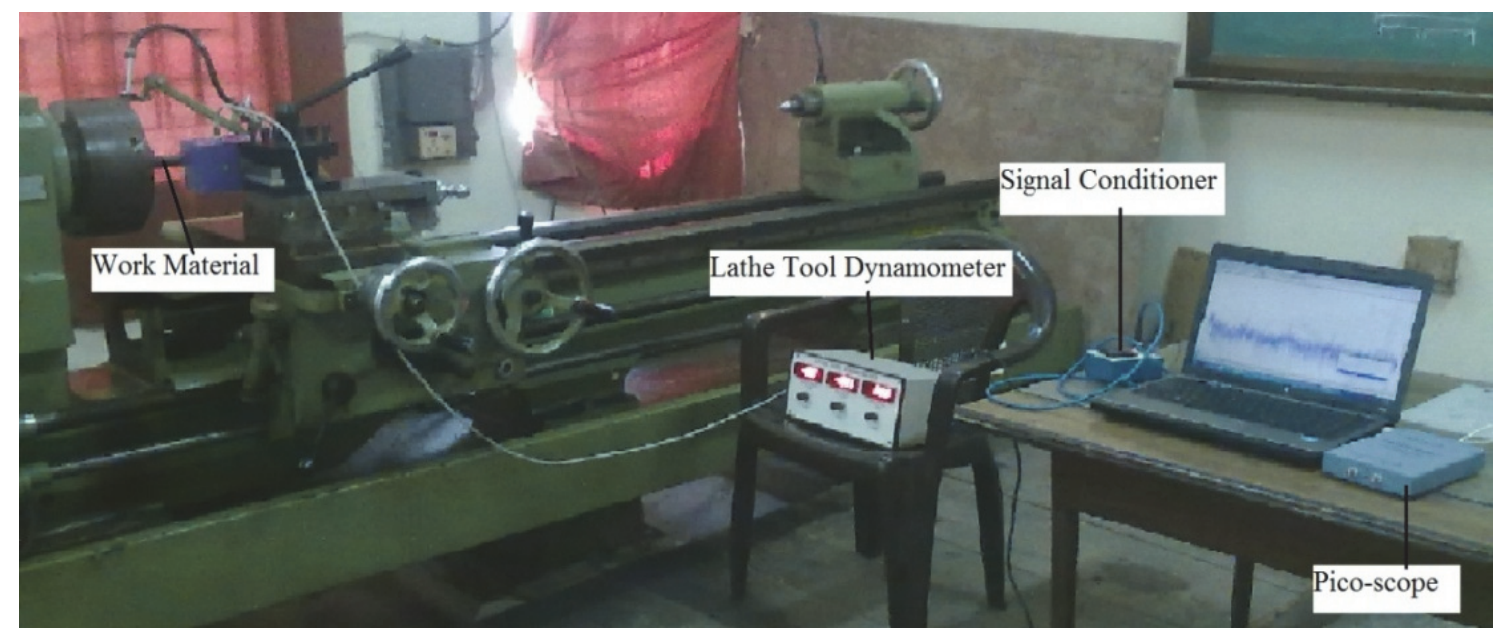

Fig. 1. Experimental Setup

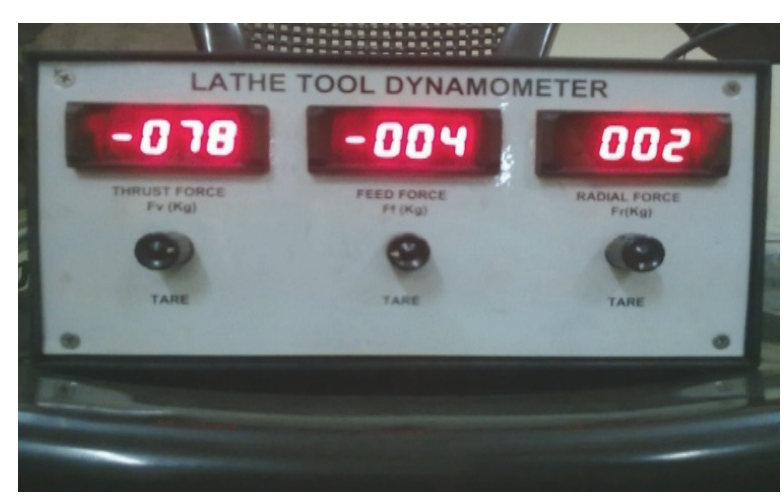

Fig. 2. Lathe Tool Dynamometer

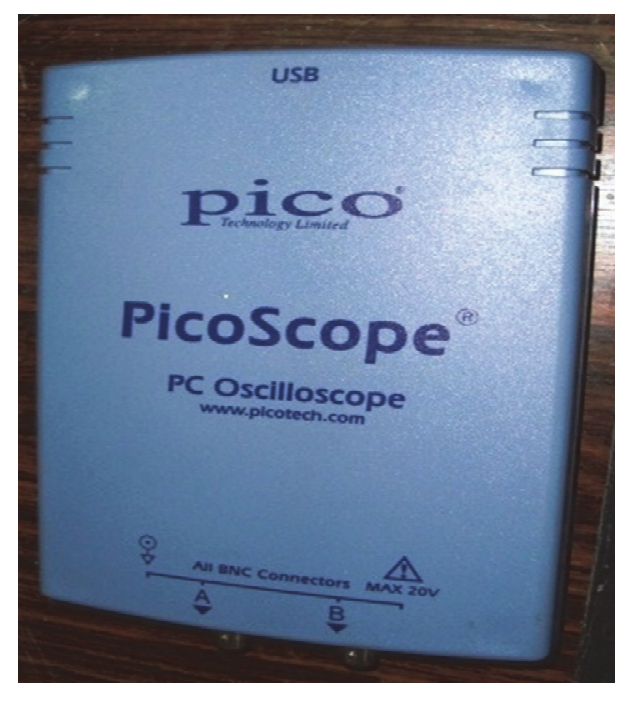

Fig. 3. PicoScope 2202

In our current investigation important machining parameters like spindle speed, depth of cut and feed rate has been studied. For experimental design Taguchi's $L_{27}$ orthogonal array has been practiced 
followed by conducting the experiments with fixed values of tool nose radius $(0.8 \mathrm{~mm})$, motor H.P (3 H.P).The assignment of the levels of the machining parameters taken for the experiments is present in Table 2.

Table 2

Input parameters and their levels

\begin{tabular}{ccccc}
\hline Machining Parameter & Symbol & Level I & Level II & Level III \\
\hline Spindle Speed (rpm.) & A & 160 & 240 & 400 \\
Depth of cut (mm.) & B & 0.1 & 0.15 & 0.2 \\
Feed rate $(\mathrm{mm} / \mathrm{rev})$. & C & 0.08 & 0.16 & 0.32 \\
\hline
\end{tabular}

\section{Table 3}

Experimental conditions and regarding response data

\begin{tabular}{|c|c|c|c|c|c|c|c|c|}
\hline \multirow[b]{2}{*}{$\begin{array}{c}\text { Experiment } \\
\text { No. }\end{array}$} & \multirow{2}{*}{$\begin{array}{l}\text { Spindle } \\
\text { Speed } \\
(\mathrm{rpm})\end{array}$} & \multirow{2}{*}{$\begin{array}{l}\text { Depth } \\
\text { of cut } \\
(\mathrm{mm})\end{array}$} & \multirow{2}{*}{$\begin{array}{l}\text { Feed rate } \\
(\mathrm{mm} / \mathrm{rev})\end{array}$} & \multicolumn{2}{|c|}{ Observed responses } & \multicolumn{3}{|c|}{ Calculated responses } \\
\hline & & & & $\begin{array}{l}\text { Cutting } \\
\text { speed } \\
(\mathrm{m} / \mathrm{min})\end{array}$ & $\begin{array}{l}\text { Force } \\
(\mathrm{N})\end{array}$ & $\begin{array}{c}\text { Power } \\
\text { calculate } \\
\text { (W) }\end{array}$ & $\begin{array}{l}\text { Average } \\
\text { surface } \\
\text { roughness } \\
\mathrm{R}_{\mathrm{a}}(\mu \mathrm{m})\end{array}$ & $\begin{array}{c}\text { Frequency of } \\
\text { tool vibration } \\
\mathrm{f}(\mathrm{Hz})\end{array}$ \\
\hline 1 & 160 & 0.15 & 0.08 & 12.56 & 47.5 & 9.94 & 1.87 & 259.25 \\
\hline 2 & 160 & 0.2 & 0.08 & 12.56 & 64 & 13.40 & 2.11 & 282 \\
\hline 3 & 160 & 0.15 & 0.32 & 12.56 & 193 & 40.40 & 5.89 & 334 \\
\hline 4 & 160 & 0.1 & 0.32 & 12.56 & 88.05 & 18.43 & 6.01 & 321.8 \\
\hline 5 & 160 & 0.1 & 0.16 & 12.56 & 43.72 & 9.15 & 2.48 & 294 \\
\hline 6 & 400 & 0.15 & 0.32 & 31.4 & 131.56 & 68.85 & 5.36 & 384 \\
\hline 7 & 240 & 0.1 & 0.16 & 18.84 & 51.65 & 16.22 & 2.27 & 316.6 \\
\hline 8 & 400 & 0.15 & 0.16 & 31.4 & 70.25 & 36.76 & 1.65 & 361 \\
\hline 9 & 160 & 0.2 & 0.16 & 12.56 & 106.38 & 22.27 & 3.07 & 312 \\
\hline 10 & 400 & 0.1 & 0.16 & 31.4 & 54.25 & 28.39 & 2.19 & 337 \\
\hline 11 & 240 & 0.15 & 0.16 & 18.84 & 81.01 & 25.44 & 2.1 & 327.8 \\
\hline 12 & 400 & 0.2 & 0.08 & 31.4 & 65 & 34.02 & 1.55 & 353 \\
\hline 13 & 240 & 0.1 & 0.32 & 18.84 & 101.01 & 31.72 & 5.94 & 348 \\
\hline 14 & 240 & 0.1 & 0.08 & 18.84 & 26 & 8.16 & 1.48 & 292 \\
\hline 15 & 240 & 0.15 & 0.08 & 18.84 & 49 & 15.39 & 1.7 & 320 \\
\hline 16 & 160 & 0.1 & 0.08 & 12.56 & 34 & 7.12 & 1.66 & 255 \\
\hline 17 & 240 & 0.2 & 0.08 & 18.84 & 64.8 & 20.35 & 1.62 & 317 \\
\hline 18 & 160 & 0.2 & 0.32 & 12.56 & 173.95 & 36.41 & 6.42 & 337 \\
\hline 19 & 400 & 0.15 & 0.08 & 31.4 & 39 & 20.41 & 1.34 & 338 \\
\hline 20 & 160 & 0.15 & 0.16 & 12.56 & 81.65 & 17.09 & 3.21 & 301.8 \\
\hline 21 & 400 & 0.2 & 0.16 & 31.4 & 128.25 & 67.12 & 2.4 & 375 \\
\hline 22 & 240 & 0.15 & 0.32 & 18.84 & 193 & 60.60 & 5.44 & 368 \\
\hline 23 & 400 & 0.1 & 0.32 & 31.4 & 108.86 & 56.97 & 5.51 & 362 \\
\hline 24 & 240 & 0.2 & 0.32 & 18.84 & 195.02 & 61.24 & 6.07 & 374.8 \\
\hline 25 & 400 & 0.2 & 0.32 & 31.4 & 175.12 & 91.65 & 5.27 & 414 \\
\hline 26 & 240 & 0.2 & 0.16 & 18.84 & 127.14 & 39.92 & 2.65 & 348 \\
\hline 27 & 400 & 0.1 & 0.08 & 31.4 & 27.12 & 14.19 & 1.27 & 323 \\
\hline
\end{tabular}

\section{Methodology}

A multi-criteria decision making model combining with MOORA-PCA and TOPSIS-PCA has been practiced for the optimization of multiple responses. The methodology of the present work is comprised of the following steps:

\subsection{Multi-objective Optimization on the Basis of Ratio Analysis (MOORA) Method}

The MCDM approach MOORA was initially suggested by Brauers and Zavadskas (2006). Brauers and Zavadskas (2009) proved that MOORA is utterly robust in decision making approaches. The following steps are followed for MCDM approach MOORA. 
Step 1: Specify the Problem

First step associated with defining the objective and to identify all desirable alternatives and its attributes.

\section{Step 2: Formation of Decision Matrix}

After identifying the objectives and alternatives the next step for MOORA is a preparation of decision matrix like other Multi Criterion Decision-Making process.

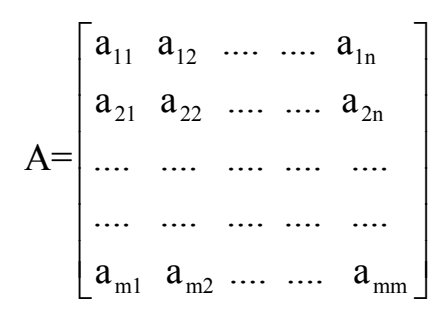

where, $a_{i j}=$ Performance measure of the $i{ }^{\text {th }}$ alternative on $j^{\text {th }}$ attribute. $m=$ No. of alternatives. $n=$ No. of attributes.

Step 3: Normalised Performance Measures

In the third step decision matrix is normalised to make it dimensionless so that we can compare all its elements. It is important to be mentioned that the criteria whether it is beneficial or non-beneficial does not effect in decision matrix normalization. This normalization procedure followed by Brauers et al. (2008) ratio system which is the square root of the sum of squares of individual alternative per criterion. It can be represented as below:

$$
\mathrm{a}_{\mathrm{ij}}{ }^{*}=\frac{\mathrm{a}_{\mathrm{ij}}}{\sqrt{\sum_{\mathrm{i}=1}^{\mathrm{m}} \mathrm{a}_{\mathrm{ij}}{ }^{2}}},
$$

where, $a_{i j}{ }^{*}$ demonstrates the normalised value $i-^{\text {th }}$ alternative on $j-^{\text {th }}$ criterion which lies between 0 and 1 .

\section{Step 4: Evaluation of Overall Assessment Value}

After finding out the normalised performance measures these are added together for larger is better or beneficial criterion and subtracted for lower is better or non-beneficial criterion. The following equation helps in the overall assessment of the performance measures:

$$
y_{i}=\sum_{j=1}^{g} a_{i j}{ }^{*}-\sum_{j=g+1}^{n} a_{i j}^{*}
$$

Usually it has been found that few of the characteristics are more influential than others. So as to give more priority to an attribute, it could be multiplied by its corresponding weight (Karande \& Chakraborty, 2012). In this case Overall Assessment Value becomes:

$$
y_{i}=\sum_{j=1}^{g} w_{j} a_{i j}{ }^{*}-\sum_{j=g+1}^{n} w_{j} a_{i j}{ }^{*} \text {, }
$$

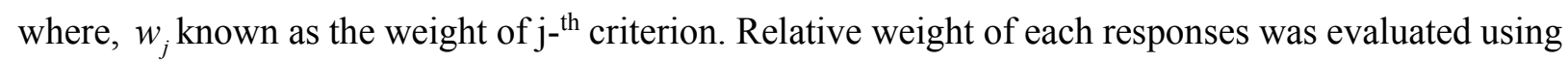
PCA. 
Step 5: Assign Ranking to Overall Assessment

At last, in descending order we sorted the Overall Assessment value. The highest value of $y_{i}$ shows the best alternative whereas the lowest value of $y_{i}$ shows the worst.

\subsection{Principal Component Analysis (PCA)}

The weightage for the individual input criterion is not the same on the output responses as it follows its comparative significance in MCDM approach. So to find out the actual weightage or percentage of each input criterion principal component analysis (PCA) was carried out.

PCA starts with multi-response array having " $n$ " investigations and "m" characteristics. In the present analysis, response parameters are retrieved after the calculation of normalised value $y_{i}$ for figure out the criteria weights. The calculation of correlation coefficient uses the equation given below: (Saha $\&$ Mondal, 2016a)

$$
R_{j l}=\left[\frac{\operatorname{cov}\left(x_{i}(j), x_{i}(l)\right)}{\sigma x_{i}(j) * \sigma x_{i}(l)}\right]
$$

where, $x_{i}(j)$ is the normalised values of each response, $\operatorname{cov}\left(x_{i}(j), x_{i}(l)\right)$ is the covariance of response variables $j$ and $l, \sigma x_{i}(j)$ and $\sigma x_{i}(l)$ are the standard deviation of response variables $j$ and $l$.

Thereafter, eigenvalues and corresponding eigenvectors are

$$
\left(R-\lambda_{x} l_{m}\right) V_{i k}=0,
$$

where, $\lambda_{x}$ eigenvalues, $\sum_{k=1}^{n}-\lambda_{k}=n ; k=1,2, \ldots \ldots . n$, and $V_{i k}\left[a_{k 1}, a_{k 2}, \ldots . . a_{k m}\right]^{T}$ are the eigen vectors corresponding to eigenvalue $\lambda_{i k}$. Thus, the principal components are

$$
Y_{m k}=\sum_{i=1}^{n} x_{m}(i) V_{i k}
$$

where, $Y_{m 1}, Y_{m 2}$ are known as the first principal component, second principal component and like this. The principal components are adjusted in descending order with respect to variance, and consequently, the first principal component $Y_{m 1}$ represents the most variance in the data.

\subsection{Technique for Order of Preference by Similarity to Ideal Solution (TOPSIS) Method}

The MCDM-based approach Technique for Order of Preference by Similarity to Ideal Solution (TOPSIS) was introduced by Hwang and Yoon (2012). The procedure consists of the following steps:

Step 1: The characteristic experimental numbers or values of alternatives at attributes $\left(\eta_{\mathrm{ij}} ; \mathrm{i}=1,2 \ldots\right.$ number of experiment $(m), j=1,2 \ldots$ number of responses $(n))$ are inputs and placed in matrix form.

$$
D=\left[\begin{array}{cccc}
\eta_{11} & \eta_{12} & \ldots . . & \eta_{1 n} \\
\eta_{21} & \eta_{22} & \ldots . . & \eta_{2 n} \\
\ldots . . & \ldots \ldots & \ldots . . & \ldots . . \\
\eta_{m 1} & \eta_{m 2} & \ldots . . & \eta_{m n}
\end{array}\right]
$$

Step 2: In the next step normalised rating is calculated by the vector normalization: 


$$
r_{i j}=\frac{\eta_{i j}}{\sqrt{\sum_{i=1}^{m} \eta_{i j}^{2}}}
$$

where, $r_{i j}$ represents the normalised value $\mathrm{i}^{\text {th }}$ alternative on $\mathrm{j}^{-{ }^{\text {th }}}$ criterion which lies between 0 and 1 .

Step 3: After calculating the corresponding weightage of each responses using PCA approach the weighted normalised decision matrix has been made. The weighted normalied value $v_{i j}$ is calculated as follows:

$$
v_{i j}=r_{i j} \times w_{j},
$$

where, $w_{j}$ is the weight of the $\mathrm{j}^{\text {th }}$ criterion or attribute and $\sum_{j=1}^{n} w_{j}=1$

Step 4: Determine the ideal $\left(\mathrm{A}^{*}\right)$ and negative ideal $\left(\mathrm{A}^{-}\right)$solutions.

The positive ideal solution, $\mathrm{A}^{*}(\mathrm{i}=1,2, \ldots, \mathrm{m})$, is made of all the best values (maximum $\mathrm{S} / \mathrm{N}$ ratio) and the negative-ideal solution, $\mathrm{A}^{-}(\mathrm{i}=1,2, \ldots, \mathrm{m})$, is made of all the worst values (minimum $\mathrm{S} / \mathrm{N}$ ratio) at the responses in the weighted normalised decision matrix $\left(\mathrm{V}_{\mathrm{ij}}\right)$ and calculated using Eq. (10) and Eq. (11) (Vommi, 2017).

$$
\begin{aligned}
& A^{*}=\left\{\left(\max _{i} v_{i j} \mid j \in C_{b}\right),\left(\min _{i} \mathcal{V}_{i j} \mid j \in C_{c}\right)\right\}=\left\{\hat{v}_{j}^{*} \mid j=1,2, \ldots, m\right\} \\
& A^{-}=\left\{\left(\min _{i} \mathcal{V}_{i j} \mid j \in C_{b}\right),\left(\max _{i} \mathcal{V}_{i j} \mid j \in C_{c}\right)\right\}=\left\{\mathcal{V}_{j}^{-} \mid j=1,2, \ldots, m\right\}
\end{aligned}
$$

Step 5: In the next step separation measures is calculated using the m-dimensional Euclidean distance. The separation measures of each alternative from the positive ideal solution and the negative ideal solution, respectively, are as follows:

$$
\begin{aligned}
& S_{i}^{*}=\sqrt{\sum_{j=1}^{m}\left(v_{i j}-v_{j}^{*}\right)^{2}} \\
& S_{i}^{-}=\sqrt{\sum_{j=1}^{m}\left(v_{i j}-v_{j}^{-}\right)^{2}}
\end{aligned}
$$

where, $j=1,2, \ldots \ldots \ldots, m$

Step 6: Calculate the relative closeness to the ideal solution. The relative closeness of the alternative $\mathrm{A}_{\mathrm{i}}$ with respect to $\mathrm{A}^{*}$ is defined as follows:

$$
R C_{i}^{*}=\frac{S_{i}^{-}}{S_{i}^{*}+S_{i}^{-}}
$$

where, $i=1,2, \ldots \ldots \ldots . ., m$

Step 7: At the last step we assign rank to all the relative closeness value after arranging them in descending order.

\section{Results and discussion}

\subsection{Multi-response optimization using MOORA-PCA}

The alternatives considered in the current work are spindle speed, depth of cut and feed rate and output attributes are power consumption $\left(\mathrm{C}_{1}\right)$, average surface roughness $\left(\mathrm{C}_{2}\right)$ and frequency of tool vibration 
$\left(\mathrm{C}_{3}\right)$. All the attributes are the non-beneficial where a lower value is preferable. While solving optimal combination of machining parameters in turning using MOORA method, the data of the decision matrix, as shown in Table 4, is first transformed into dimensionless values using linear normalization procedure, so that all these criteria can be comparable. Using Eq. (3) the normalized value of each performance measure has been computed as shown in Table 4.

In further step, the relative weights of each performance characteristics was evaluated (Table 5 and 6), using the PCA method, according to Eq. (7). The square value of the eigenvalues implies the contribution of the related quality characteristics to principal component analysis. Different contributions are determined for power consumption, average surface roughness and frequency of tool vibration as $0.3881,0.2470$ and 0.3648 , respectively. In addition, the variance contribution for the $1^{\text {st }}$ principal component indicating the three responses is as high as $78.1 \%$. Accordingly, in the present work, the squares of its subsequent eigenvectors $Y_{i m}$ are preferred as weighing values of the associated responses, and coefficients of $a_{i j}^{*}$, i.e., $w_{1}, w_{2}$ and $w_{3}$ in Eq. (5) are thus put as $0.3881,0.2470$ and 0.3648 respectively. Finally, using Eq. (5) overall assessment value $\left(y_{i}\right)$ has been evaluated and displayed in Table 7. As stated in MOORA method, each assessment value arranged in descending order and then ranking have been assigned. It has been found that experiment no. 16 has the maximum $y_{i}$ value. Thus, an optimum combination of machining parameters for the multi-criteria characteristics should be selected as A1B1C1, namely spindle speed: $160 \mathrm{rpm}$, depth-of-cut: $0.1 \mathrm{~mm}$. and feed rate: $0.08 \mathrm{~mm} / \mathrm{rev}$. Fig. 6 shows the overall assessment value graph of each level of the turning parameters. The higher the overall assessment value, the better multiple quality characteristics were.

Table 4

Decision matrix and Normalized data matrix for optimal cutting parameters selection problem

\begin{tabular}{ccccccc}
\hline & \multicolumn{5}{c}{ Decision matrix } & \multicolumn{3}{c}{ Normalized Value } \\
\cline { 2 - 6 } Serial No. & $\mathrm{C}_{1}$ & $\mathrm{C}_{2}$ & $\mathrm{C} 3$ & $\mathrm{C} 1$ & $\mathrm{C} 2$ & $\mathrm{C} 3$ \\
\hline $\mathrm{A}_{1}$ & 9.94 & 1.87 & 259.25 & 0.049 & 0.096 & 0.150 \\
$\mathrm{~A}_{2}$ & 13.40 & 2.11 & 282 & 0.066 & 0.108 & 0.163 \\
$\mathrm{~A}_{3}$ & 40.40 & 5.89 & 334 & 0.200 & 0.302 & 0.193 \\
$\mathrm{~A}_{4}$ & 18.43 & 6.01 & 321.8 & 0.091 & 0.308 & 0.186 \\
$\mathrm{~A}_{5}$ & 0.99 & 2.48 & 294 & 0.045 & 0.127 & 0.170 \\
$\mathrm{~A}_{6}$ & 68.85 & 5.36 & 384 & 0.340 & 0.275 & 0.221 \\
$\mathrm{~A}_{7}$ & 16.22 & 2.27 & 316.6 & 0.080 & 0.116 & 0.183 \\
$\mathrm{~A}_{8}$ & 36.76 & 1.65 & 361 & 0.182 & 0.085 & 0.208 \\
$\mathrm{~A}_{9}$ & 22.27 & 3.07 & 312 & 0.110 & 0.157 & 0.180 \\
$\mathrm{~A}_{10}$ & 28.39 & 2.19 & 337 & 0.140 & 0.112 & 0.194 \\
$\mathrm{~A}_{11}$ & 25.44 & 2.1 & 327.8 & 0.126 & 0.108 & 0.189 \\
$\mathrm{~A}_{12}$ & 34.02 & 1.55 & 353 & 0.168 & 0.079 & 0.204 \\
$\mathrm{~A}_{13}$ & 31.72 & 5.94 & 348 & 0.157 & 0.304 & 0.201 \\
$\mathrm{~A}_{14}$ & 8.16 & 1.48 & 292 & 0.040 & 0.076 & 0.168 \\
$\mathrm{~A}_{15}$ & 15.39 & 1.7 & 320 & 0.076 & 0.087 & 0.185 \\
$\mathrm{~A}_{16}$ & 7.12 & 1.66 & 255 & 0.035 & 0.085 & 0.147 \\
$\mathrm{~A}_{17}$ & 20.35 & 1.62 & 317 & 0.101 & 0.083 & 0.183 \\
$\mathrm{~A}_{18}$ & 36.41 & 6.42 & 337 & 0.180 & 0.329 & 0.194 \\
$\mathrm{~A}_{19}$ & 20.41 & 1.34 & 338 & 0.101 & 0.069 & 0.195 \\
$\mathrm{~A}_{20}$ & 17.09 & 3.21 & 301.8 & 0.084 & 0.165 & 0.174 \\
$\mathrm{~A}_{21}$ & 67.12 & 2.4 & 375 & 0.332 & 0.123 & 0.216 \\
$\mathrm{~A}_{22}$ & 60.60 & 5.44 & 368 & 0.299 & 0.279 & 0.212 \\
$\mathrm{~A}_{23}$ & 56.97 & 5.51 & 362 & 0.281 & 0.282 & 0.209 \\
$\mathrm{~A}_{24}$ & 61.24 & 6.07 & 374.8 & 0.303 & 0.311 & 0.216 \\
$\mathrm{~A}_{25}$ & 91.65 & 5.27 & 414 & 0.453 & 0.270 & 0.239 \\
$\mathrm{~A}_{26}$ & 39.92 & 2.65 & 348 & 0.197 & 0.136 & 0.201 \\
$\mathrm{~A}_{27}$ & 14.19 & 1.27 & 323 & 0.070 & 0.065 & 0.186 \\
\hline & & & & & \\
\hline
\end{tabular}


Table 5

Eigenvalues and proportions of principal components

\begin{tabular}{ccc}
\hline Principal component & Eigenvalues & Proportion (\%) \\
\hline First & 2.3423 & 78.1 \\
Second & 0.5670 & 18.9 \\
Third & 0.0907 & 3.0 \\
\hline
\end{tabular}

Table 6

Eigenvectors for principal components and contribution

\begin{tabular}{lcccc}
\hline Quality Characteristics & \multicolumn{4}{c}{ Eigenvectors } \\
\cline { 2 - 5 } & $\begin{array}{c}1^{\text {st }} \text { Principal } \\
\text { component }\end{array}$ & $\begin{array}{c}2^{\text {nd }} \text { Principal } \\
\text { component }\end{array}$ & $\begin{array}{c}3^{\text {rd }} \text { Principal } \\
\text { component }\end{array}$ & Contribution $\left(\beta_{\mathrm{j}}\right)$ \\
\hline Power Consumption $\left(\mathrm{C}_{1}\right)$ & 0.623 & -0.271 & -0.734 & 0.3881 \\
Average Surface roughness $\left(\mathrm{C}_{2}\right)$ & 0.497 & 0.862 & 0.104 & 0.2470 \\
Frequency of tool vibration $\left(C_{3}\right)$ & 0.604 & -0.429 & 0.672 & 0.3648 \\
\hline
\end{tabular}

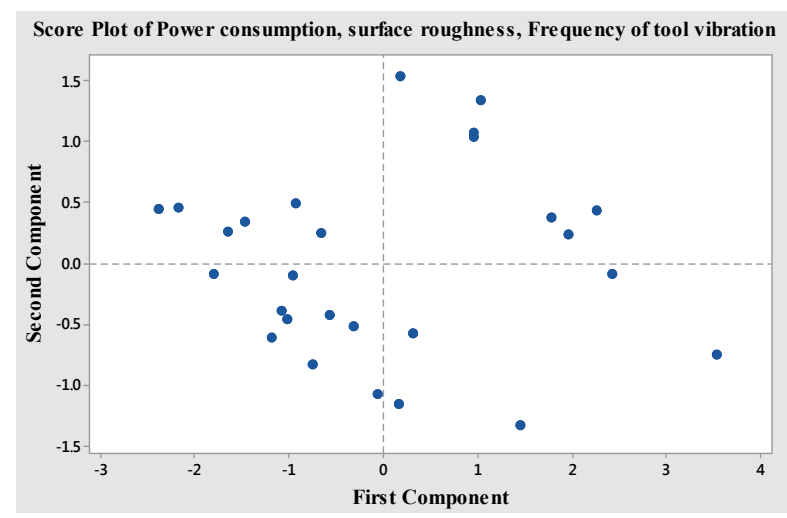

Fig. 4. Score Plot of performance characteristics

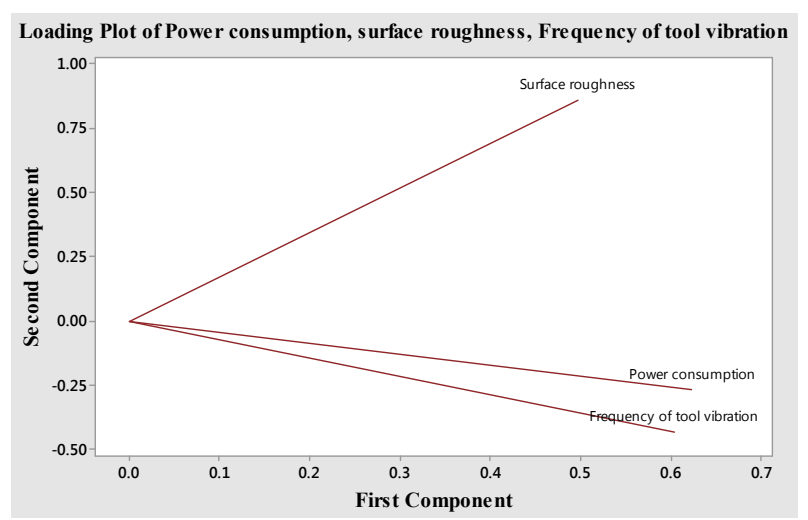

Fig. 5. Loading Plot of performance characteristics

Fig. 4 shows the score plot of power consumption, surface roughness and frequency of tool vibration. It is used to plot the scores for the second principal component (y-axis) versus the scores for the first principal component (x-axis). Fig. 5 shows the loading plot of power consumption, surface roughness and frequency of tool vibration. It is used to plot the loadings for the second component (y-axis) versus the loadings for the first component (x-axis).

Table 7

Overall assessment value by MOORA-PCA

\begin{tabular}{|c|c|c|c|c|c|}
\hline Sl. No. & $\mathrm{y}_{\mathrm{i}}$ & Rank & S1. No. & $\mathrm{y}_{\mathrm{i}}$ & Rank \\
\hline $\mathrm{A}_{1}$ & -0.097 & 3 & $\mathrm{~A}_{15}$ & -0.118 & 7 \\
\hline $\mathrm{A}_{2}$ & -0.112 & 6 & $\mathrm{~A}_{16}$ & -0.088 & 1 \\
\hline $\mathrm{A}_{3}$ & -0.222 & 21 & $\mathrm{~A}_{17}$ & -0.126 & 8 \\
\hline $\mathrm{A}_{4}$ & -0.179 & 17 & $\mathrm{~A}_{18}$ & -0.222 & 20 \\
\hline $\mathrm{A}_{5}$ & -0.111 & 4 & $\mathrm{~A}_{19}$ & -0.127 & 10 \\
\hline $\mathrm{A}_{6}$ & -0.281 & 26 & $\mathrm{~A}_{20}$ & -0.137 & 11 \\
\hline $\mathrm{A}_{7}$ & -0.126 & 9 & $\mathrm{~A}_{21}$ & -0.238 & 22 \\
\hline $\mathrm{A}_{8}$ & -0.167 & 16 & $\mathrm{~A}_{22}$ & -0.262 & 24 \\
\hline $\mathrm{A}_{9}$ & -0.147 & 13 & $\mathrm{~A}_{23}$ & -0.255 & 23 \\
\hline $\mathrm{A}_{10}$ & -0.153 & 14 & $\mathrm{~A}_{24}$ & -0.273 & 25 \\
\hline $\mathrm{A}_{11}$ & -0.144 & 12 & $\mathrm{~A}_{25}$ & -0.330 & 27 \\
\hline $\mathrm{A}_{12}$ & -0.159 & 15 & $\mathrm{~A}_{26}$ & -0.183 & 18 \\
\hline $\mathrm{A}_{13}$ & -0.209 & 19 & $\mathrm{~A}_{27}$ & -0.111 & 5 \\
\hline $\mathrm{A}_{14}$ & -0.096 & 2 & & & \\
\hline
\end{tabular}




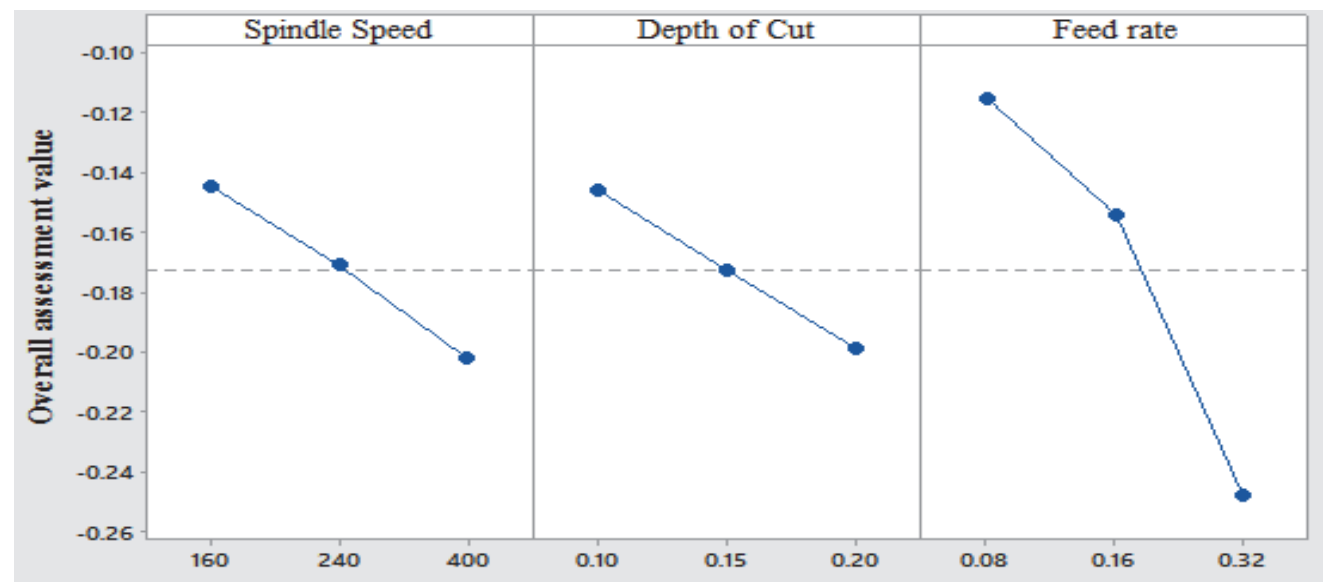

Fig. 6. Overall assessment value graph

\subsection{Multi-response optimization using TOPSIS-PCA Approach}

To convert the MCDM problem into a single response problem, the TOPSIS method is used. The $\mathrm{S} / \mathrm{N}$ ratios $[\eta(d B)]$ are calculated to study the quality characteristic of the experiment. Later on the relative weights of each performance characteristics were evaluated using PCA method (Tables 5-6). Weighted normalized values for all quality characteristics in each experimental run are determined using Eq. (11). Next, the positive ideal solution $\left(\mathrm{A}^{*}\right)$ and negative ideal solutions $\left(\mathrm{A}^{-}\right)$were calculated using Eq. (12) and Eq. (13). Finally, Eq. (16) is used to calculate the similarity of the ideal solutions in each scenario (Table 8). Ranking has been assigned according to TOPSIS method for each assessment value after arranging them in descending order. It was found that experiment no. 14 having the highest relative closeness $\left(\mathrm{RC}_{\mathrm{i}}^{*}\right)$ value. Thus the optimum combination of process parameters for the multiple quality characteristics should be selected as A2B1C1, namely spindle speed: $240 \mathrm{rpm}$, depth-of-cut: $0.1 \mathrm{~mm}$. and feed rate: $0.08 \mathrm{~mm} / \mathrm{rev}$.

\section{Table 8}

Closeness coefficient values and ranking of alternatives

\begin{tabular}{|c|c|c|c|c|}
\hline Experiment No. & $S_{i}^{*}$ & $S_{i}$ & $R C_{i}^{*}$ & Rank \\
\hline 1 & 0.071 & 0.266 & 1.071 & 5 \\
\hline 2 & 0.063 & 0.250 & 1.063 & 9 \\
\hline 3 & 0.019 & 0.138 & 1.019 & 22 \\
\hline 4 & 0.036 & 0.191 & 1.036 & 19 \\
\hline 5 & 0.065 & 0.255 & 1.065 & 8 \\
\hline 6 & 0.010 & 0.099 & 1.010 & 25 \\
\hline 7 & 0.058 & 0.240 & 1.058 & 12 \\
\hline 8 & 0.059 & 0.243 & 1.059 & 11 \\
\hline 9 & 0.044 & 0.209 & 1.044 & 16 \\
\hline 10 & 0.051 & 0.226 & 1.051 & 14 \\
\hline 11 & 0.054 & 0.232 & 1.054 & 13 \\
\hline 12 & 0.062 & 0.249 & 1.062 & 10 \\
\hline 13 & 0.024 & 0.156 & 1.024 & 20 \\
\hline 14 & 0.081 & 0.284 & 1.081 & 1 \\
\hline 15 & 0.067 & 0.259 & 1.067 & 6 \\
\hline 16 & 0.080 & 0.282 & 1.080 & 2 \\
\hline 17 & 0.065 & 0.256 & 1.065 & 7 \\
\hline 18 & 0.021 & 0.145 & 1.021 & 21 \\
\hline 19 & 0.072 & 0.268 & 1.072 & 4 \\
\hline 20 & 0.047 & 0.217 & 1.047 & 15 \\
\hline 21 & 0.041 & 0.201 & 1.041 & 17 \\
\hline 22 & 0.012 & 0.108 & 1.012 & 24 \\
\hline 23 & 0.012 & 0.112 & 1.012 & 23 \\
\hline 24 & 0.009 & 0.097 & 1.009 & 26 \\
\hline 25 & 0.008 & 0.089 & 1.008 & 27 \\
\hline 26 & 0.041 & 0.201 & 1.041 & 18 \\
\hline 27 & 0.078 & 0.279 & 1.078 & 3 \\
\hline
\end{tabular}




\subsection{Comparison between MOORA-PCA and TOPSIS-PCA method}

According to MOORA-PCA method, the optimum combination of the input parameters is: A1B1C1 (i.e. spindle speed: $160 \mathrm{rpm}$, depth of cut: $0.1 \mathrm{~mm}$. and feed rate: $0.08 \mathrm{~mm} / \mathrm{rev}$ ). In TOPSIS-PCA approach, an optimum combination of process parameters should be selected as A2B1C1, namely spindle speed: $240 \mathrm{rpm}$, depth-of-cut: $0.1 \mathrm{~mm}$. and feed rate: $0.08 \mathrm{~mm} / \mathrm{rev}$. The results of MOORAPCA and TOPSIS-PCA approach are compared and found that the optimal values of power consumption is $7.12 \mathrm{~W}$ and frequency of tool vibration is $255 \mathrm{~Hz}$ using MOORA-PCA while in TOPSIS-PCA is $8.16 \mathrm{~W}$ for power consumption and frequency of tool vibration is $292 \mathrm{~Hz}$. The hybrid MOORA-PCA approach takes the advantages over the other approaches by keeping consistency of judgment due to associated weights easing mutual interactive effect and optimization of machining parameters is based on both subjective and objective factors using PCA. This is easy to create and separates most significant information from the data. Main weak points in TOPSIS method are ranked based on the closeness coefficient values that solves the multi-response problem by establishing the Euclidean distance function which measures the distance from the ideal solution and also methodology fails to relate the machining and performance characteristics.

\subsection{Contour Plot of Overall Assessment Value vs. Output Responses}

Fig. 7 interprets the inter-relationship amongst operating parameters, Depth of cut and Spindle speed and Overall assessment value keeping Feed rate constant at their mid values. We see from the above figure that Overall assessment value tends to decrease with increase in Depth of cut and Spindle speed.

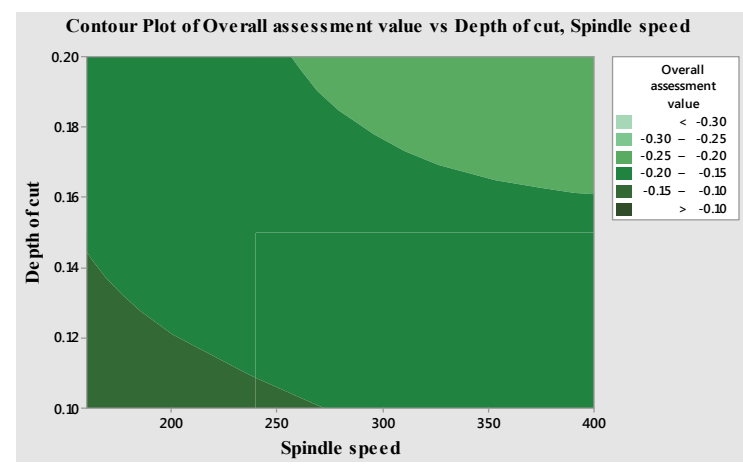

Fig. 7. Contour Plot of Overall assessment value vs. Depth of cut and Spindle speed

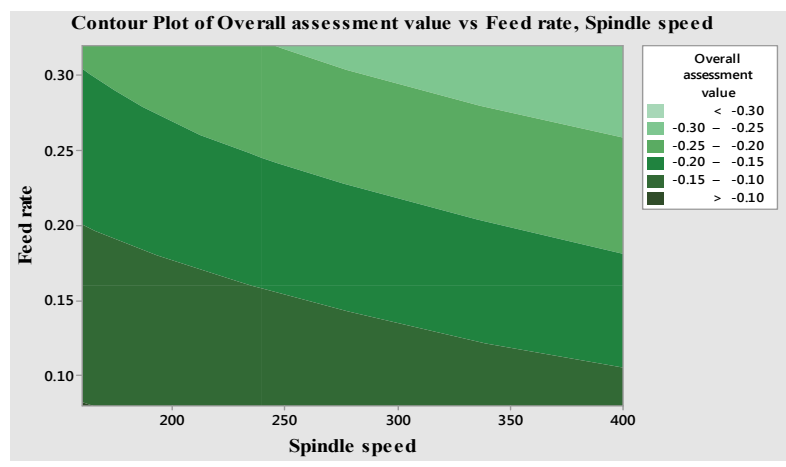

Fig. 8. Contour Plot of Overall assessment value vs. Feed rate and Spindle speed

From Fig. 8 an approximately linear relationship has been found among Feed rate and Spindle speed and Overall assessment value. Overall assessment value gradually decreases with the increase of Feed rate and Spindle speed. Fig. 9 gives the graphical representation of the relation among Feed rate and Depth of cut and Overall assessment value. From the above figure it is clearly visible that highest value of Feed rate and Depth of cut gives the lowest value of Overall assessment.

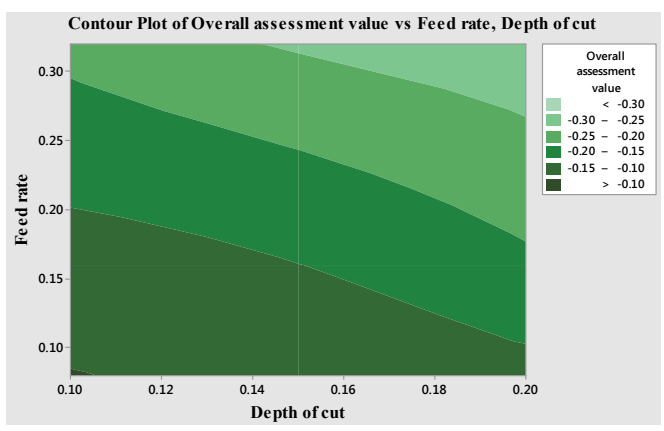

Fig. 9. Contour Plot of Overall assessment value vs. Feed rate and Depth of cut 


\section{Conclusions}

In the present study, the work material made of ASTM A588 mild steel was machined according to Taguchi's $\mathrm{L}_{27}$ orthogonal array. The results were optimized simultaneously using hybrid optimization tool viz. MOORA-PCA and TOPSIS-PCA approach. On the basis of the investigation results, the accompanying conclusions might be drawn:

1. The optimum combination for the hybrid MOORA-PCA approach found as A1B1C1 (i.e. spindle speed: $160 \mathrm{rpm}$, depth of cut: $0.1 \mathrm{~mm}$. and feed rate: $0.08 \mathrm{~mm} / \mathrm{rev}$ ). Whereas the optimum combination for the hybrid TOPSIS-PCA approach corresponds to A2B1C1 (i.e. spindle speed: $240 \mathrm{rpm}$, depth of cut: $0.1 \mathrm{~mm}$. and feed rate: $0.08 \mathrm{~mm} / \mathrm{rev}$ ).

2. Comparison between MOORA-PCA and TOPSIS-PCA shows the advantage of MOORA over TOPSIS method in optimizing the output responses in the present experimental environment.

3. Contour graphs of output responses with overall assessment value shows the relation between them.

4. The MOORA coupled with PCA strategy can be considered as a more helpful methodology than different other Multi Criteria Selection approaches because of its capacity to clarify process fluctuation. A weighted estimation of every quality attributes has been proposed, which diminishes the many-sided quality of the choice making methodology.

5. The proposed multi criteria decision making methodology requires very less mathematical calculations and also relatively easier than that of other conventional methods. Hence, it can be practiced in different machining environment where various responses are to be optimized simultaneously.

The results obtained in this work can be used as standards both academic research and industrial applications. However, the effects of input parameters on other important process outputs, such as tool wear, cutting temperature, surface morphology etc. was not investigated. These effects can be analyzed in future works.

\section{References}

Antony, J. (2000). Multi-response optimization in industrial experiments using Taguchi's quality loss function and principal components analysis. Quality and reliability engineering international, 16(1), 38.

Brauers, W. K. M., \& Zavadskas, E. K. (2006). The MOORA method and its application to privatization in a transition economy. Control and Cybernetics, 35(2), 445.

Brauers, W. K. M., \& Zavadskas, E. K. (2009). Robustness of the multi-objective MOORA method with a test for the facilities sector. Technological and Economic Development of Economy, 2, 352-375.

Brauers, W. K. M., Zavadskas, E. K., Peldschus, F., \& Turskis, Z. (2008). Multi-objective optimization of road design alternatives with an application of the MOORA method. Proceedings of the $25^{\text {th }}$ International Symposium on Automation and Robotics in Construction, Lithuania, 541-548.

Davim, J. P., Gaitonde, V., \& Karnik, S. (2008). Investigations into the effect of cutting conditions on surface roughness in turning of free machining steel by ANN models. Journal of Materials Processing Technology, 205(1), 16-23.

Dey, S., \& Chakraborty, S. (2016). A study on the machinability of some metal alloys using grey TOPSIS method. Decision Science Letters, 5(1), 31-44.

Gadakh, V. (2010). Application of MOORA method for parametric optimization of milling process. International Journal of Applied Engineering Research, 1(4), 743.

Gadakh, V., Shinde, V., \& Khemnar, N. (2013). Optimization of welding process parameters using MOORA method. The International Journal of Advanced Manufacturing Technology, 69(9-12), 20312039. 
Hwang, C.-L., \& Yoon, K. (2012). Multiple attribute decision making: methods and applications a state-ofthe-art survey. Springer Science \& Business Media, 186.

Jean, M.-D., \& Wang, J.-T. (2006). Using a principal components analysis for developing a robust design of electron beam welding. The International Journal of Advanced Manufacturing Technology, 28(9), 882-889.

Karande, P., \& Chakraborty, S. (2012). Application of multi-objective optimization on the basis of ratio analysis (MOORA) method for materials selection. Materials \& Design, 37, 317-324.

Khan, A., \& Maity, K. (2016a). Application of MCDM-based TOPSIS method for the optimization of multi quality characteristics of modern manufacturing processes. International Journal of Engineering Research in Africa, 23, 33-51.

Khan, A., \& Maity, K. (2016b). A novel MCDM approach for simultaneous optimization of some correlated machining parameters in Turning of CP-Titanium Grade 2. International Journal of Engineering Research in Africa, 22, 94-111.

Khan, A., \& Maity, K. (2016c). Parametric optimization of some non-conventional machining processes using MOORA method. International Journal of Engineering Research in Africa, 20, 19-40.

Lin, C. (2004). Use of the Taguchi method and grey relational analysis to optimize turning operations with multiple performance characteristics. Materials and manufacturing processes, 19(2), 209-220.

Majumder, H., Paul, T., Dey, V., Dutta, P., \& Saha, A. (2017). Use of PCA-Grey analysis and rsm to model cutting time and surface finish of INCONEL 800 during wire elctro discharge cutting. Measurement, 107, 19-30.

Muthukrishnan, N., \& Davim, J. P. (2009). Optimization of machining parameters of Al/SiC-MMC with ANOVA and ANN analysis. Journal of Materials Processing Technology, 209(1), 225-232.

Özel, T., Karpat, Y., Figueira, L., \& Davim, J. P. (2007). Modelling of surface finish and tool flank wear in turning of AISI D2 steel with ceramic wiper inserts. Journal of Materials Processing Technology, 189(1), 192-198.

Palanikumar, K. (2006). Cutting parameters optimization for surface roughness in machining of GFRP composites using Taguchi's method. Journal of Reinforced Plastics and Composites, 25(16), 1739-1751.

Peason, K. (1901). On lines and planes of closest fit to systems of point in space. Philosophical Magazine, 2(11), 559-572.

Ray, A. (2016). Optimization of process parameters of green electrical discharge machining using principal component analysis (PCA). The International Journal of Advanced Manufacturing Technology, 87(58), 1299-1311.

Saha, A., \& Mondal, S. C. (2016a) Multi-objective optimization of welding parameters in MMAW for nanostructured hardfacing material using GRA coupled with PCA. Transactions of the Indian Institute of Metals, 1-12.

Saha, A., \& Mondal, S. C. (2016b). Experimental investigation and modelling of WEDM process for machining nano-structured hardfacing material. Journal of the Brazilian Society of Mechanical Sciences and Engineering, 1-17.

Saha, A., \& Mondal, S. C. (2016c). Multi-objective optimization in WEDM process of nanostructured hardfacing materials through hybrid techniques. Measurement, 94, 46-59.

Vommi, V. (2017). TOPSIS with statistical distances: A new approach to MADM. Decision Science Letters, $6(1), 49-66$.

Wang, M., \& Lan, T. (2008). Parametric optimization on multi-objective precision turning using grey relational analysis. Information Technology Journal, 7(7), 1072-1076.

Yih-Fong, T., \& Fu-Chen, C. (2006). Multiobjective process optimisation for turning of tool steels. International Journal of Machining and Machinability of Materials, 1(1), 76-93.

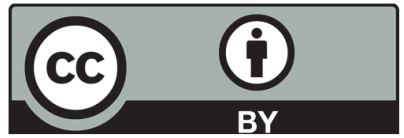

(C) 2017 by the authors; licensee Growing Science, Canada. This is an open access article distributed under the terms and conditions of the Creative Commons Attribution (CC-BY) license (http://creativecommons.org/licenses/by/4.0/). 